\title{
Pharmacokinetics, Biotransformation, Distribution and Excretion of Empagli- flozin, a Sodium-Glucose Co-Transporter (SGLT 2) Inhibitor, in Mice, Rats, and Dogs
}

\author{
Chen $\mathrm{L}^{* 1}$, Mao $\mathrm{Y}^{1}$, Sharp DE ${ }^{1}$, Schadt $\mathrm{S}^{2,5}$, Pagels $\mathrm{S}^{1}$, Press $\mathrm{R}^{3}$, Cheng $\mathrm{T}^{3}$, Potchoiba $\mathrm{MJ}^{3}$ and Collins $\mathrm{W}^{4}$ \\ ${ }^{1}$ Boehringer Ingelheim Pharmaceuticals, Inc., Ridgefield, CT, USA
}

${ }^{2}$ Boehringer Ingelheim Pharma GmbH \& Co. KG, Biberach an der Riss, Germany

${ }^{3}$ Covance Laboratories, Inc., Madison, WI, USA

${ }^{4}$ XenoBiotic Laboratories, Inc., Plainsboro, NJ, USA

${ }^{5}$ F. Hoffmann-La Roche Ltd, Basel, Switzerland

*Corresponding author: Chen L, Ph.D., Drug Metabolism and Pharmacokinetics US, Boehringer Ingelheim Pharmaceuticals, Inc., 900 Ridgebury Road, P.O. Box 368, Ridgefield, CT, USA 06877, Fax: 203-791-6003, Tel: 203-778-7870,E-mail: Lin_zhi.chen@boehringer-ingelheim.com

Citation: Chen L, Mao Y, Sharp DE, Schadt S, Pagels S, et al. (2015) Pharmacokinetics, Biotransformation, Distribution and Excretion of Empagliflozin, a Sodium-Glucose Co-Transporter (SGLT 2) Inhibitor, in Mice, Rats, and Dogs. J Pharm Drug Devel 3(3): 302. doi: 10.15744/2348-9782.3.302

Received Date: March 23, 2015 Accepted Date: June 22, 2015 Published Date: June 24, 2015

\begin{abstract}
The metabolism, pharmacokinetics, excretion and distribution of a sodium-glucose co-transporter (SGLT 2) inhibitor, empagliflozin, were studied in mice, rats and beagle dogs following a single oral or intravenous administration of $\left[{ }^{14} \mathrm{C}\right]$-empagliflozin. Empagliflozin was well absorbed in all species after oral administration. The clearance of empagliflozin was low in dog and moderate in mice and rats. Volume of distribution and half-life were generally moderate in all species. Oral bioavailability was moderate in rats (31\%) and high in mice (90-97\%) and dogs (89\%). The pharmacokinetics of $\left[{ }^{14} \mathrm{C}\right]$-empagliflozin-related radioactivity after intravenous administration was characterized by a short $\mathrm{t}^{1} \frac{2}{2}$ in mice and rats and a long $\mathrm{t}^{1} / 2$ in dogs, consistent with the circulating radioactivity being predominately empagliflozin. The $t^{1} / 2$ of $\left[{ }^{14} \mathrm{C}\right]$-empagliflozin-related radioactivity after oral administration was longer, suggesting circulating metabolites. The tissue distribution of $\left[{ }^{14} \mathrm{C}\right]$-empagliflozin-related radioactivity in male rats following oral administration was limited and most of the radioactivity was found in the contents of the gastrointestinal tract and the major organs of elimination. Elimination was complete for all tissues by $72 \mathrm{hr}$ post-dose.

Excretion patterns were generally similar in males and females across species evaluated. Feces was the primary route of excretion of $\left[{ }^{14} \mathrm{C}\right]$-empagliflozin-derived radioactivity. Biotransformation of empagliflozin mainly involved oxidation as well as glucuronide and glucose conjugation. Several minor metabolites were found in dogs but not in mice and rats.
\end{abstract}

Keywords: LC/MS; Metabolite profiling; Metabolite identification; QWBA; Mass balance; Pharmacokinetics

\section{Introduction}

Type 2 diabetes mellitus (T2DM) is a chronic disease characterized by hyperglycemia caused by progressive beta-cell failure [1]. The prevalence and incidence of T2DM are increasing worldwide [2]. In the US and Europe, T2DM is the leading cause of cardiovascular disorders, blindness, end-stage renal disease and amputations [3]. The ultimate aim of managing patients with T2DM is to control glycaemia and thus prevent or delay the development of complications. However, despite the availability of many drugs to treat T2DM at a variety of pharmacologic targets, many patients fail to achieve recommended glycemic targets [4].

The sodium glucose co-transporter 2 (SGLT2), located in the proximal tubule, is the transporter primarily responsible for reabsorption of glucose filtered by the kidney [5]. In healthy individuals, virtually all of the $\sim 180$ g/day of glucose filtered by the kidney is reabsorbed into the bloodstream [6]. Inhibition of SGLT2 reduces renal glucose reabsorption and increases urinary glucose excretion (UGE), thereby reducing hyperglycaemia in patients with T2DM [5].

Empagliflozin is a potent and selective SGLT2 inhibitor [7] developed as a treatment for T2DM and approved by US Food and Drug Administration in 2014. Empagliflozin provides a sustained increase in urinary glucose excretion in patients with T2DM [8]. In Phase III trials in patients with T2DM, empagliflozin given as monotherapy or as an add-on to other diabetes therapies was consistently shown to improve glycaemic control, reduce body weight and blood pressure, and to be well tolerated, with a low risk of hypoglycaemia [9-13]. 
The present study was conducted to study the pharmacokinetics, absorption, distribution, metabolism and excretion (ADME) of empagliflozin in CD-1 mice, Wistar Han rats and beagle dogs. Metabolite profiles in plasma, urine, bile and feces were determined and the metabolites identification was performed using high-performance liquid chromatography (HPLC) coupled with radiodetection and tandem mass spectrometry (MS/MS).

\section{Material and Methods}

\section{Chemicals and solvents}

The liquid scintillation cocktails Permafluor and Ultima Gold and the absorbent Carbo-Sorb were obtained from Perkin Elmer (Rodgau, Germany or Shelton, CT, USA). All other chemicals and solvents were HPLC or analytical grade and obtained from reliable commercial sources.

\section{Radiolabeled drug and reference standards}

$\left[{ }^{14} \mathrm{C}\right]$-empagliflozin, non-labeled empagliflozin and metabolite reference standards were provided by Boehringer Ingelheim Pharmaceuticals, Inc., Ridgefield, CT. Chemical identities of these compounds were established by HPLC, MS and NMR. The specific activity of $\left[{ }^{14} \mathrm{C}\right]$-empagliflozin was $0.845 \mu \mathrm{Ci} / \mu \mathrm{mol}$ for the mouse and rat and $1.64 \mu \mathrm{Ci} / \mu \mathrm{mol}$ for the dog studies, except for the rat IV $(53.6 \mu \mathrm{Ci} / \mu \mathrm{mol})$ and $\mathrm{PO}(13.7 \mu \mathrm{Ci} / \mu \mathrm{mol})$ studies. $\left[{ }^{14} \mathrm{C}\right]$-empagliflozin radiochemical purity was determined to be $>97 \%$ by $\mathrm{LC} /$ radiochromatography. The structure of $\left[{ }^{14} \mathrm{C}\right]$-empagliflozin is shown in Figure 1.

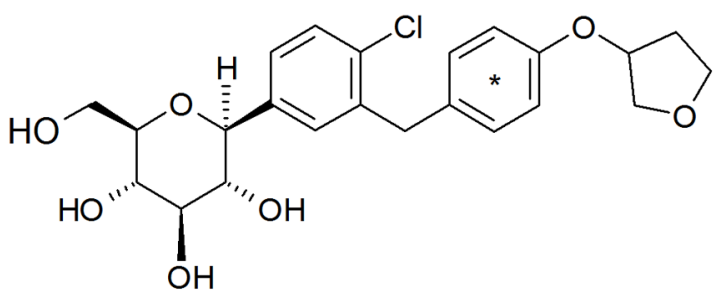

\section{Animals}

Figure 1: Structure of $\left[{ }^{14} \mathrm{C}\right]$-empagliflozin

For the pharmacokinetic and mass balance studies, CD-1 mice and Wistar Han rats (Crl:WI(Han)) were obtained from Charles River Laboratories, Kingston, NY and Raleigh, NC, respectively. Rats for bile collection were fitted with a bile duct cannula by Charles River. Beagle dogs for the mass balance and PK studies were obtained from the in house colonies of Covance Laboratories, Madison, WI. Study protocols were approved by the local Institutional Animal Care and Use Committee.

\section{Mouse and rat mass balance studies}

The mass balance studies were conducted in male and female mice and rats and the doses were administered as solutions. Details on the formulations and doses administered are provided in the supplementary material. Each animal received a single $\left[{ }^{14} \mathrm{C}\right]-$ empagliflozin dose by intravenous (IV) $(5 \mathrm{mg} / \mathrm{kg}$ for mice and $0.5 \mathrm{mg} / \mathrm{kg}$ for rats) or per oral (PO) (250 mg/kg for mice and 5 $\mathrm{mg} / \mathrm{kg}$ for rats) at a dose level based upon individual body weights taken prior to dosing. The actual amount of dose formulation administered to each animal was determined by weighing the loaded dose syringe before dose administration and the emptied syringe after dose administration.

Urine was collected on dry ice at 24-h intervals for $168 \mathrm{~h}$. Feces were collected on dry ice (mice and rats) at 24-h intervals for 168 h. Cages were rinsed at 24-h intervals post-dose.

Bile was obtained from male rats after PO dose and collected on dry ice hourly for $8 \mathrm{~h}$, and then from 8-24 and 24-48 h postdose.

\section{Mouse and rat PK studies}

Pharmacokinetic studies were conducted in CD-1 mice and Wistar Han rats after a single PO or IV dose of $\left[{ }^{14} \mathrm{C}\right]$-empagliflozin $\left({ }^{14} \mathrm{C}\right.$ $\mathrm{PK}$ ) or unlabeled empagliflozin (cold PK). The rat PK studies with unlabeled empagliflozin were conducted only in male animals as per our normal procedure. Blood was collected from $4 \mathrm{mice} / \mathrm{sex} /$ time point in tubes containing $\mathrm{K}_{3}$ EDTA as the anticoagulant from the retro-orbital venous plexus at $0.33,1,2,4,6,8$, and $24 \mathrm{~h}$ after dosing. Blood was collected from rats via a jugular vein cannula with $\mathrm{K}_{3}$ EDTA as the anticoagulant at $0.25,0.5,1,2,4,6,8$, and $24 \mathrm{~h}$ after dosing. Blood obtained via cardiac puncture were collected from separate mice and rats for metabolite identification. Plasma samples were prepared by centrifugation of the whole blood. Plasma samples were stored at approximately $-20^{\circ} \mathrm{C}$ prior to analysis.

\section{Dog mass balance and PK study}

The PK studies with unlabeled empagliflozin were conducted only in male dogs as per our normal procedure. The radiolabeled studies were conducted in dogs of both sexes. The volume of radiolabeled dose formulation administered to each dog was calculated based on the body weight taken on the day of dosing. The actual amount administered was determined by weighing the dose syringe before and after dose administration. The IV dose was administered via a cephalic vein and the oral dose was administered via oral gavage. 
Blood was collected via a jugular vein into tubes containing $\mathrm{K}_{3}$ EDTA from 3 animals/sex/time point/route at predose, 0.0167 (IV only), 0.25 (IV only), $0.5,1,2,3,4,6,8,24,30,48,72,96,120,144$, and 168 h postdose. An additional blood was collected from the orally dosed dogs at 1,4 , and $8 \mathrm{~h}$ for metabolite profiling. Blood samples were placed in a chilled Kryorack until aliquoted and centrifuged to obtain plasma. Urine was collected on dry ice at 24 -h intervals for $168 \mathrm{~h}$. Feces were collected at room temperature at 24 -h intervals for $168 \mathrm{~h}$. Cages were rinsed at 24-h intervals post-dose.

\section{QWBA study}

The Quantitative Whole-Body Autoradiography (QWBA) study was conducted in male rats following a single PO dose of $\left[{ }^{14} \mathrm{C}\right]-$ empagliflozin. Each animal received a single $\left[{ }^{14} \mathrm{C}\right]$-empagliflozin dose by oral gavage at a dose level based upon individual body weights taken prior to dosing. Rats were euthanized by an overdose of isoflurane anesthesia. The carcasses were frozen in a hexane dry ice bath and stored at $-20^{\circ} \mathrm{C}$. The carcasses were embedded in carboxymethyl cellulose blocks. Blood samples fortified with $\left[{ }^{14} \mathrm{C}\right]$-empagliflozin were placed in to the frozen block to serve as standards. Sagittal sections (40 $\mu \mathrm{m}$ thick) at five levels of interest were prepared in a Leica CM 3600 cryomicrotome. Mounted sections were wrapped with Mylar film and exposed to phosphorimaging screens for 4 days. Exposed screens were scanned using an Amersham Biosciences Storm. Tissue concentrations were interpolated from the standard curve.

\section{PK analysis}

PK parameters were calculated from blood and plasma radioactivity concentration data using WinNonlin Professional Edition, Version 5.2 (Certara Corporation, St. Louis MO) for dogs and Kinetica Version 4.4.1 (Thermo Scientific, Philadelphia, PA) for rats and mice. PK parameters calculated included half-life $\left(t_{1 / 2}\right)$, area under the concentration-time curve from time 0 to the last measurable time point $\left(\mathrm{AUC}_{0-\mathrm{t}}\right)$, and area under the concentration-time curve from 0 to infinity $\left(\mathrm{AUC}_{0-\infty}\right)$. A concentration of " 0 " $\mu \mathrm{M}$ was assumed for the predose concentrations as well as for those samples with levels below the lower limit of quantitation.

\section{Sample preparation and analysis}

Analysis of Radioactivity: Feces were homogenized in water (mouse and rat) or 20: 80 ethanol: water (dog). Fecal homogenates for rat and dog were combusted in a Packard 307 Sample Oxidizer (Perkin Elmer, Waltham, MA, USA) and the resulting $\left[{ }^{14} \mathrm{C}\right]-\mathrm{CO}_{2}$ was trapped in Carbo-Sorb. Mouse fecal homogenates were combusted in a Harvey Biological Sample oxidizer and the resulting $\left[{ }^{14} \mathrm{C}\right]-\mathrm{CO}_{2}$ was trapped in Harvey Scintillation. Levels of radioactivity in plasma, urine, bile, cage rinse/wash and $\mathrm{CO}_{2}$-trap samples were analyzed by LSC (Models Tricarb 2900 Perkin Elmer, Waltham, MA, USA). Scintillation counting data expressed in counts/ min $(\mathrm{cpm})$ were automatically corrected for counting efficiency using the external standardization technique and an instrument stored quench curve.

Metabolite Profiling/id: Mouse, rat and dog plasma samples collected at different time points following oral administration of $\left[{ }^{14} \mathrm{C}\right]$-empagliflozin were pooled according to gender and time point. The pooled plasma samples were diluted with water and then extracted using Waters Oasis MCX $20 \mathrm{cc} / 1 \mathrm{~g}$ solid phase extraction (SPE) cartridges (Waters, Milford, MA). After loading, the SPE cartridge was washed with $0.5 \%$ acetic acid or $0.1 \mathrm{~N} \mathrm{HCl}$, water and $5 \%$ methanol in water, and eluted with methanol. The eluate was concentrated under $37^{\circ} \mathrm{C}$ with a Zymark Turbovap LV (GenTech Scientific, Inc. New York, NY) or similar evaporator, and reconstituted in methanol and water for analysis. The overall extraction recovery of radioactivity from plasma was $\geq 87.1 \%$.

Urine collected from 0-24 h (mouse), 0-120 h (rats) or 0-24 h period (dogs) was pooled at equal percentages (by volume) according to gender; this represented $\geq 93.9 \%$ of the total radioactivity excreted in urine from rats, mice or dogs. For analysis, the pooled urine was prepared by centrifugation (mice) or by SPE (rats and dogs) following the similar SPE procedures for plasma. The overall extraction recovery of radioactivity from urine was $\geq 95.9 \%$.

Homogenate of feces collected up through $48 \mathrm{~h}$ (mice and dogs) or $72 \mathrm{~h}$ (rats) were pooled at equal percentages (by weight) according to gender, and this represented $\geq 97.3 \%$ of total radioactivity excreted in feces from mice, rats or dogs. The pooled fecal homogenate was centrifuged, and the resultant pellet was extracted with methanol, acetonitrile and $10 \%$ acetic acid in methanol. The extracts were combined with the supernatant and concentrated at $37^{\circ} \mathrm{C}$. For mice, the concentrated samples were centrifuged prior to analysis. For rats and dogs, the concentrated samples were diluted with water and then extracted with SPE following the procedure used for plasma extraction. The overall extraction recovery of radioactivity from feces was $\geq 89.5 \%$.

Rat bile was collected up to 48 hours post-dose from 4 male rats after single oral administration of $\left[{ }^{14} \mathrm{C}\right]-\mathrm{BI} 10773(5 \mathrm{mg} / \mathrm{kg})$. For metabolite profiling, all available 2 to 48 -hr bile samples were combined, diluted with methanol at a ratio of $7: 3$ (bile : methanol; $\mathrm{v}: \mathrm{v})$ and centrifuged, and resulting supernatant was separated for analysis.

Metabolite profiling and identification was carried out with an LC/radio-detection/MS system. The system consisted of an Agilent 1100 or 1200 HPLC system (Agilent, Palo Alto, CA) with a LTQ Orbitrap mass spectrometer (Thermo Scientific, San Jose, CA) and a flow scintillation analyzer serving as detectors. An ARCTM (AIM Research Co., Hockessin, DE), PerkinElmer 625 TR (PerkinElmer, Shelton, CT) or Radioflow detector LB 509 (Berthold, Bad Wildbad, Germany) was used as the flow scintillation analyzer. The MS and flow scintillation analyzers functioned in parallel by splitting the $0.6 \mathrm{~mL} / \mathrm{min}$ flow from the HPLC column in a 1:20 (or 1:10 for mouse) ratio, with one part going to the mass spectrometry and 20 (or 10) parts to the flow scintillation analyzer. 
Fraction collection followed by offline radioactivity counting was used for mouse 8-h plasma due to the low radioactivity in the samples. The instrument setup was the same as the online LC/radiometric/MS system, except that the flow scintillation detector was replaced with a Gilson 204 fraction collector (Gilson, Middleton, WI). The LC fractions were collected in 96-well Scintiplates or Deepwell LumaPlates ${ }^{\mathrm{TM}}$ (PerkinElmer, Shelton, CT) which had solid scintillant embedded. The plates were dried using a miVac modular concentrator at $37{ }^{\circ} \mathrm{C}$ and then counted with a MicroBeta Trilux 1450 LSC and Luminescence counter or a TopCount NXT counter (PerkinElmer, Shelton, CT). Radiochromatograms were reconstructed using ARC ${ }^{\text {TM }}$ Data System (AIM Research Co., Hockessin, DE) or FractionLynx software (Waters, Milford, MA).

Metabolite separation was achieved using a reversed-phase HPLC column (Atlantis ${ }^{\mathrm{TM}} \mathrm{dC1}$, 150 x 3.9 mm, $3 \mu \mathrm{m}$; Waters, Milford, MA). Mobile phase A comprised of 90:5:5 $\mathrm{H}_{2} \mathrm{O}: \mathrm{MeOH}: 100 \mathrm{mM}$ ammonium acetate and mobile phase B was 95:5 MeOH: 100 mM ammonium acetate. The gradient conditions were from $100 \%$ to $80 \%$ A over $20 \mathrm{~min}$, to $55 \%$ A over $30 \mathrm{~min}$, to $20 \% \mathrm{~A}$ over $20 \mathrm{~min}$, and then to $0 \% \mathrm{~A}$ and hold for $8 \mathrm{~min}$ at $0.6 \mathrm{~mL} / \mathrm{min}$.

The LTQ Orbitrap mass spectrometer was equipped with a Thermo Scientific electrospray ion source or a Triversa Nanomate ${ }^{\mathrm{TM}}$ nanoflow ion source (Advion Biosciences, Ithaca, NY) and operated in positive or negative mode. Key electrospray ion source operating parameters included: spray voltage, $+5 \mathrm{kV}$ (positive mode)/-4.5 kV (negative mode); sheath gas, 35/15 units; auxiliary, 5/1 unites; capillary temperature, $275^{\circ} \mathrm{C}$; tube lens, $-103 / 158 \mathrm{~V}$; resolution, 30,000 . The Nanomate ${ }^{\mathrm{TM}}$ was operated using an $\mathrm{x} 400 / 5$ $\mu \mathrm{m}$ id nozzle chip at $+/-1.5 \mathrm{kV}$. Thermo Scientific MetWorks 1.2 software with mass defect filter was used to assist metabolite identification.

\section{Results}

\section{PK of empagliflozin}

Summaries of the pharmacokinetic parameters of plasma empagliflozin and total radioactivity in mice, rats, and dogs are found in the supplemental material.

After IV dosing of $5 \mathrm{mg} / \mathrm{kg}$ to mice, the mean $\mathrm{AUC}_{0-\infty}$ of plasma total radioactivity was 4.61 and $5.60 \mu \mathrm{M} . \mathrm{h}$ in male and female mice, respectively. The terminal $t_{1 / 2}$ was short, at $1.26 \mathrm{~h}$ for males and $0.65 \mathrm{~h}$ for females. The mean residence times (MRT) were 0.49 and $0.43 \mathrm{~h}$, in males and females, respectively. After oral dosing at $250 \mathrm{mg} / \mathrm{kg}$ to mice, empagliflozin was rapidly absorbed with a $t_{\max }$ of $0.67 \mathrm{~h}$ and $0.33 \mathrm{~h}$ in males and females, respectively. $\mathrm{C}_{\max }$ values were $97.7 \mu \mathrm{M}$ and $91.5 \mu \mathrm{M}$ in male and female mice, respectively. $\mathrm{AUC}_{0-\infty}$ values were $207 \mu \mathrm{Mh}$ and $273 \mu \mathrm{Mh}$ in males and females, respectively. Terminal $\mathrm{t}_{1 / 2}$ was long, at $5.59 \mathrm{~h}$ for males and $4.31 \mathrm{~h}$ for females. The bioavailability of empagliflozin was $89.8 \%$ and $96.7 \%$, respectively, in male and female mice.

After IV dosing of $0.5 \mathrm{mg} / \mathrm{kg}$ to male rats, the mean $\mathrm{AUC}_{0-\infty}$ of empagliflozin was $1.32 \mu \mathrm{Mh}$. The terminal $\mathrm{t}_{1 / 2}$ was moderate at 3.64 $\mathrm{h}$. The MRT was $0.83 \mathrm{~h}$. After oral dosing at $5 \mathrm{mg}$ to male rats, the median $\mathrm{t}_{\max }$ of empagliflozin occurred at $1 \mathrm{~h}$. The $\mathrm{C}_{\max }$ and $\mathrm{AUC}_{0}$ values were $0.724 \mu \mathrm{M}$ and $3.99 \mu \mathrm{M} \bullet \mathrm{h}$, respectively. The terminal $\mathrm{t}_{1 / 2}$ was long, at $6.32 \mathrm{~h}$. The bioavailability of empagliflozin was $31.0 \%$ in male rats.

After IV dosing of $0.5 \mathrm{mg} / \mathrm{kg}$ to male dogs, the mean $\mathrm{AUC}_{0-\infty}$ empagliflozin was $10.6 \mu \mathrm{M} \bullet \mathrm{h}$. The terminal $\mathrm{t}_{1 / 2}$ was moderate at 6.27 $\mathrm{h}$ and the MRT was $5.32 \mathrm{~h}$. The clearance value was $1.77 \mathrm{~mL} / \mathrm{min} / \mathrm{kg}$ and the Vss value was $0.568 \mathrm{~L} / \mathrm{kg}$. After oral dosing of $5 \mathrm{mg} /$ $\mathrm{kg}$ to dogs, the $\mathrm{t}_{\max }$ of total radioactivity occurred at $1 \mathrm{~h}$. $\mathrm{C}_{\max }$ was $17.3 \mu \mathrm{M}$. The $\mathrm{AUC}_{0-\infty}$ value was $93.7 \mu \mathrm{M} \bullet \mathrm{h}$. The terminal half-life was moderate with a $t_{1 / 2}$ of 6.25 h. The bioavailability of empagliflozin was $89.0 \%$ in male dogs.

\section{PK of total radioactivity}

After IV dosing of $5 \mathrm{mg} / \mathrm{kg}$ to mice, the mean $\mathrm{AUC}_{0-\infty}$ of plasma total radioactivity was 11.1 and $9.51 \mu \mathrm{M} \bullet \mathrm{h}$ in male and female mice, respectively. The terminal $t_{1 / 2}$ was short, at $0.98 \mathrm{~h}$ for males and $0.95 \mathrm{~h}$ for females. The MRT were 1.26 and $0.93 \mathrm{~h}$, in males and females respectively. After oral dosing at $250 \mathrm{mg} / \mathrm{kg}$ to mice, plasma total radioactivity was rapidly absorbed with a $\mathrm{t}_{\max }$ of $1 \mathrm{~h}$ and $0.33 \mathrm{~h}$ in males and females, respectively. $\mathrm{C}_{\max }$ values were $121 \mu \mathrm{M}$ and $117 \mu \mathrm{M}$ in male and female mice, respectively. AUC ${ }_{0-\infty}$ values were $452 \mu \mathrm{M} \bullet \mathrm{h}$ and $386 \mu \mathrm{M} \bullet \mathrm{h}$ in males and females, respectively. Terminal $\mathrm{t}_{1 / 2}$ was long, at $7.89 \mathrm{~h}$ for males and $12 \mathrm{~h}$ for females.

After IV dosing of $0.5 \mathrm{mg} / \mathrm{kg}$ to rats, the mean $\mathrm{AUC}_{0-\infty}$ of plasma total radioactivity was 1.34 and $1.51 \mu \mathrm{M} \bullet \mathrm{h}$ in male and female rats, respectively. The terminal $\mathrm{t}_{1 / 2}$ was short, at $0.67 \mathrm{~h}$ for males and $1.10 \mathrm{~h}$ for females. The MRT were 0.59 and $0.6 \mathrm{~h}$, in males and females respectively. After oral dosing at $5 \mathrm{mg} / \mathrm{kg}$ to rats, the median $\mathrm{t}_{\max }$ of plasma total radioactivity occurred at $1 \mathrm{~h}$ in both sexes. $\mathrm{C}_{\max }$ values were $1.27 \mu \mathrm{M}$ and $1.10 \mu \mathrm{M}$ in male and female rats respectively. AUC $\mathrm{A}_{0-\infty}$ values were $4.67 \mu \mathrm{M} \bullet \mathrm{h}$, and $4.20 \mu \mathrm{M} \bullet \mathrm{h}$ in males and females, respectively. The terminal $\mathrm{t}_{1 / 2}$ was moderate, at $1.75 \mathrm{~h}$ for males and $1.89 \mathrm{~h}$ for females.

After IV dosing of $0.5 \mathrm{mg} / \mathrm{kg}$ to dogs, the mean $\mathrm{AUC}_{0-\infty}$ of plasma total radioactivity was 10.2 and $10.8 \mu \mathrm{M} \bullet \mathrm{h}$ in male and female dogs, respectively. The terminal $t_{1 / 2}$ was long, at $22.0 \mathrm{~h}$ for males and $31.2 \mathrm{~h}$ for females. Clearance values were $1.76 \mathrm{and} 1.65 \mathrm{~mL} /$ $\mathrm{min} / \mathrm{kg}$ in males and females, respectively with an overall mean of $1.71 \mathrm{~mL} / \mathrm{min} / \mathrm{kg}$. In males and females, Vss values were 0.836 and $1.08 \mathrm{~L} / \mathrm{kg}$, respectively, and the MRT were 7.87 and $10.9 \mathrm{~h}$, respectively. After oral dosing at $5 \mathrm{mg} / \mathrm{kg}$ to dogs, the $\mathrm{t}_{\max }$ of total radioactivity occurred at $1 \mathrm{~h}$ in both males and females. $\mathrm{C}_{\max }$ values were 16.1 and $15.5 \mu \mathrm{M}$ in male and female dogs, respectively. AUC $_{0-\infty}$ values were $101 \mu \mathrm{M} \bullet \mathrm{h}$, and $96.3 \mu \mathrm{M} \bullet \mathrm{h}$ in males and females, respectively. The terminal half-life was moderate with a $\mathrm{t}_{1 / 2}$ 
of $3.60 \mathrm{~h}$ in males and $5.16 \mathrm{~h}$ in females. The shorter half-life observed in orally dosed animals than in intravenously dosed dogs is due to the lower limit of quantitation found in the intravenously dosed animals, which enabled a larger portion of the terminal elimination phase to be measured. Absorption of drug-derived radioactivity was 102 and $92.1 \%$ in males and females, respectively.

\section{Mass balance and excretion}

After oral administration of $250 \mathrm{mg} / \mathrm{kg}$ of $\left[{ }^{14} \mathrm{C}\right]$-empagliflozin to male and female mice, $36.4 \%$ and $48.0 \%$ of the radioactive dose was recovered in urine and feces, respectively, from male mice, whereas approximately $44.6 \%$ and $40.7 \%$ of the radioactive dose was recovered in urine and feces, respectively, from female mice (Table 1). The mean recovery was 96.1 and $95.2 \%$ of dose in males and females, respectively.

\begin{tabular}{|c|c|c|c|c|c|c|c|}
\hline \multicolumn{8}{|c|}{ \% Radioactivity Dose } \\
\hline Species & Route & $\begin{array}{c}\text { Dose } \\
(\mathrm{mg} / \mathrm{kg})\end{array}$ & Sex & $\begin{array}{c}\text { No. of } \\
\text { Animals }\end{array}$ & Urine & Feces & Total * \\
\hline \multirow{2}{*}{ Mouse } & \multirow{2}{*}{ Oral } & \multirow{2}{*}{250} & M & 9 & $36.4 \pm 5.5$ & $48.0 \pm 4.7$ & $96.1 \pm 0.98$ \\
\hline & & & $\mathrm{F}$ & 9 & $44.6 \pm 3.3$ & $40.7 \pm 1.8$ & $95.2 \pm 0.76$ \\
\hline \multirow{4}{*}{ Rat } & \multirow{2}{*}{ IV } & \multirow{2}{*}{0.5} & M & 4 & $27.5 \pm 3.8$ & $64.4 \pm 2.5$ & $92.2 \pm 1.6$ \\
\hline & & & $\mathrm{F}$ & 4 & $28.5 \pm 3.2$ & $61.4 \pm 2.7$ & $90.9 \pm 1.5$ \\
\hline & \multirow{2}{*}{ Oral } & \multirow{2}{*}{5} & M & 4 & $27.4 \pm 6.2$ & $62.9 \pm 7.3$ & $92.9 \pm 1.4$ \\
\hline & & & $\mathrm{F}$ & 4 & $28.6 \pm 3.9$ & $63.1 \pm 5.7$ & $92.6 \pm 2.5$ \\
\hline \multirow{4}{*}{ Dog } & \multirow{2}{*}{ IV } & \multirow{2}{*}{0.5} & M & 3 & $17.4 \pm 1.6$ & $70.9 \pm 2.2$ & $92.4 \pm 2.2$ \\
\hline & & & $\mathrm{F}$ & 3 & $24.6 \pm 3.9$ & $68.6 \pm 2.6$ & $94.7 \pm 1.3$ \\
\hline & \multirow{2}{*}{ Oral } & \multirow{2}{*}{5} & M & 3 & $29.6 \pm 2.7$ & $61.4 \pm 2.4$ & $93.7 \pm 0.4$ \\
\hline & & & $\mathrm{F}$ & 3 & $19.6 \pm 3.0$ & $69.8 \pm 1.2$ & $91.1 \pm 2.7$ \\
\hline
\end{tabular}

\footnotetext{
* Total percent of radioactivity recovered includes cage wash and cage wipe
}

Table 1: Percentage of radioactive dose recovery in mice, rats and dogs

Following a single IV dose of $0.5 \mathrm{mg} / \mathrm{kg}$ of $\left[{ }^{14} \mathrm{C}\right]$-empagliflozin to male and female rats, the primary route for elimination of drug-derived radioactivity was via feces (Table 1). In males, feces and urine accounted for mean values of 64.4 and $27.5 \%$ of the administered dose, respectively. In females, feces and urine represented 61.4 and $28.5 \%$ of dose, respectively. The mean overall recoveries in males and females were 92.2 and $90.9 \%$ of dose, respectively. After oral administration of $5 \mathrm{mg} / \mathrm{kg}$ of $\left[{ }^{14} \mathrm{C}\right]-$ empagliflozin to male and female rats, $27.4 \%$ and $28.6 \%$ of the total administered radioactive dose was excreted in urine within 168 $\mathrm{h}$ (Table 1) in male and female rats, respectively. The respective recovery in the feces was $62.9 \%$ and $63.1 \%$ of the dose. The total recovery was $92.9 \%$ and $92.6 \%$ of dose in males and females respectively. There was no sex difference in excretion.

In bile duct-cannulated male rats, $33.3 \%$ of the dose was excreted by $48 \mathrm{~h}$ post dose (not shown in the table).

Following a single IV dose of $0.5 \mathrm{mg} / \mathrm{kg}$ of $\left[{ }^{14} \mathrm{C}\right]$-empagliflozin, the primary route for elimination of drug-derived radioactivity in male and female dogs was via feces (Table 1). In males, feces and urine accounted for mean values of 70.9 and $17.4 \%$ of the administered dose, respectively. In females, feces and urine represented 68.6 and $24.6 \%$ of dose, respectively. The mean overall recoveries in males and females were 92.4 and $94.7 \%$ of dose, respectively. Similar to the IV group, the primary elimination route was via feces following a single oral dose of $5 \mathrm{mg} / \mathrm{kg}$ of $\left[{ }^{14} \mathrm{C}\right]$-empaglifozin to dogs (Table 1 ). In males, feces and urine accounted for mean values of 61.4 and $29.6 \%$ of the administered dose, respectively. In females, feces and urine represented 69.8 and $19.6 \%$ of dose, respectively. The mean overall recoveries in males and females were 93.7 and $91.1 \%$ of dose, respectively.

\section{Metabolite Profiles in Plasma}

Metabolite profiling was conducted using plasma from mice, rats and dogs in the oral dose groups only. Plasma samples were obtained at 1,6, and $24 \mathrm{~h}$ for mice, 1 and 8 hours for rats and 1, 4 and 8 hours for dog following a single oral administration of $\left[{ }^{14} \mathrm{C}\right]$-empagliflozin at $250 \mathrm{mg} / \mathrm{kg}$ (mice) or $5 \mathrm{mg} / \mathrm{kg}$ (rats and dogs). These time points represented most of the plasma radioactivity in each species. Relative contributions of empagliflozin and its metabolites to plasma radioactivity are listed in Table 2. To facilitate interspecies comparison, the relative contributions were calculated for the total plasma (AUC) of respective time points for each species. Representative radiochromatogram of 1-h male rat plasma is shown in Figure 2. Empagliflozin was the most abundant drug-related component in all the three species (Table 2), accounting for $40.9 \%$ (males) and $93.2 \%$ (females) of the plasma radioactivity for mice, $54.3 \%$ (males) and $59.3 \%$ (females) for rats, and 78.0\% (males) and $82.0 \%$ (females) for dogs. Twelve metabolites were found in dog plasma, seven were found in the mouse plasma and six were seen in the rat plasma. In all the three species, a tetrahydrofuran-ring-opened carboxylic acid metabolite (M482/1) was the most abundant metabolite, which accounted for $39.3 \%$ (males) and $5.0 \%$ (females) of plasma radioactivity in mice, $30.4 \%$ (males) and $17.7 \%$ (females) in rats, and 9.4\% (males) and 6.6\% (females) in dogs. Other relative abundant metabolites included a destetrahydrofuranyl metabolite M380/1 (0.2 - 2.4\% in mice, $5.3-5.4 \%$ in rat and $1.2-1.8 \%$ in dogs), a tetrahydrofuran ring-opened dihydroxyl metabolite M468/1 (0.4 - 3.6\% in mice, $3.9-5.3 \%$ in rat and $0.7-1.0 \%$ in dogs), an oxidation-dehydrogenation metabolite M464/1 (0.4 - 3.8\% in mice, $4.9-5.0 \%$ in rats 
and $0.7-1.1 \%$ in dogs), and a glucuronide metabolite M626/3 (0.1 - 6.0\% in mice, 0.7 - 1.1\% in dog; not found in rats). The remaining metabolites were much less abundant and each represented for $\leq 5.9 \%$ of plasma radioactivity in all three species. These minor metabolites included M498/1 (a triple oxidation/tetrahydrofuran ring-opened metabolite), M482/2 (a carboxylic acid metabolite isomeric to M482/1), an acid metabolite (M464/2), a cyclic ester metabolite (M464/3), a cyclic ester-carboxylic metabolite (M478/1), deschlorination metabolite (M418/1), as well as four glucuronide conjugates (M556/1, M626/1, M626/2 and M626/3).

\begin{tabular}{|l|c|c|c|c|c|c|}
\hline \multirow{2}{*}{} & \multicolumn{5}{|c|}{ \% Plasma Radioactivity* } \\
\cline { 2 - 8 } & \multicolumn{2}{|c}{ Mouse } & \multicolumn{2}{c|}{ Rat } & \multicolumn{2}{c|}{ Dog } \\
\cline { 2 - 8 } & $\mathbf{2 5 0} \mathbf{~ m g / k g}$ & \multicolumn{2}{c|}{$\mathbf{5}$ mg/kg } & \multicolumn{2}{c|}{$\mathbf{~ m g / k g}$} \\
\cline { 2 - 8 } & Male & Female & Male & Female & Male & Female \\
\hline Empagliflozin & 40.8 & 93.2 & 54.3 & 59.3 & 78.0 & 82.0 \\
\hline M556/1 & 3.7 & 0.2 & - & - & 0.4 & 0.6 \\
\hline M498/1 & 0.3 & - & - & 5.9 & & \\
\hline M482/2 & - & - & - & - & 3.1 & 2.9 \\
\hline M482/1 & 39.3 & 5.0 & 30.4 & 17.7 & 9.4 & 6.6 \\
\hline M626/1 & - & - & - & - & 0.2 & 0.1 \\
\hline M478/1 & - & - & - & - & 0.9 & 0.6 \\
\hline M380/1 & 2.4 & 0.2 & 5.3 & 5.4 & 1.8 & 1.2 \\
\hline M468/1 & 3.6 & 0.4 & 3.9 & 5.3 & 1.0 & 0.7 \\
\hline M418/1 & - & - & 1.2 & 1.6 & - & - \\
\hline M626/2 & - & - & - & - & 0.3 & 0.5 \\
\hline M464/2 & - & - & - & - & 2.8 & 2.2 \\
\hline M464/3 & - & - & - & - & 0.1 & 0.1 \\
\hline M626/3 & 6.1 & 0.1 & - & - & 1.3 & 1.4 \\
\hline M464/1 & 3.8 & 0.4 & 5.0 & 4.9 & 0.7 & 1.1 \\
\hline Total** & 100 & 99.5 & 100 & 100 & 97.8 & 96.2 \\
\hline
\end{tabular}

- Not detected ${ }^{*} \%$ Plasma radioactivity is calculated using $\mathrm{AUC}_{0-24 \mathrm{~h}}$ for mice and $\mathrm{AUC}_{0 .-\mathrm{sh}}$ for rats and dogs, ${ }^{* *}$ Remaining radioactivity was contributed by one or more metabolite, each $\leq 1.1 \%$ of plasma radioactivity

Table 2: Relative distribution (\%AUC) of empagliflozin and metabolites in plasma from mice, rats and dogs after oral dosing of $\left[{ }^{14} \mathrm{C}\right]$ empagliflozin
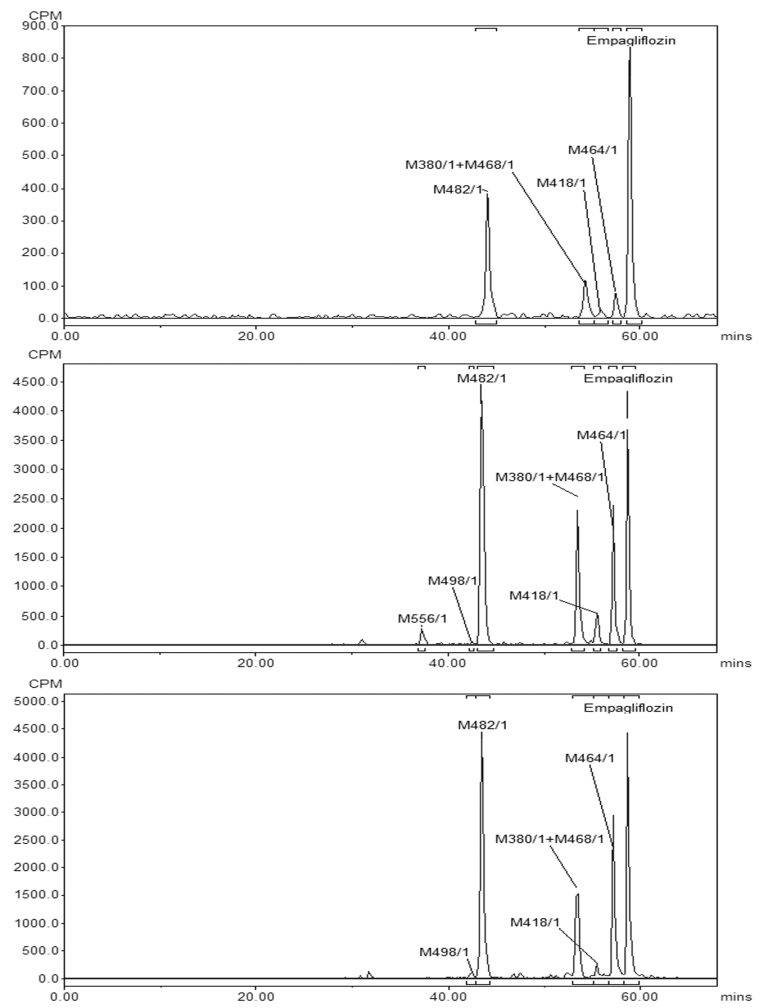

Figure 2: Radiochromatograms of pooled 1-h plasma (top), urine (middle) and feces (bottom) from male rats 


\section{Metabolite profiles in urine}

Unchanged empagliflozin in urine contributed to $2.2-16.2 \%$ of administrated dose in mice, $6.9-10.0 \%$ in rats, and $7.1-9.6 \%$ in dogs (Table 3). Representative radio chromatogram of male rat urine is shown in Figure 2. Similar to plasma, more urinary metabolites were found in dogs than in mice or rats and M482/1 being the most abundant metabolite in all the three species. M482/1 accounted for $15.6-17.5 \%, 5.9-9.8 \%$ and $6.8-11.3 \%$ of radioactivity dose in the mouse, rat and dog urine, respectively. All other metabolites were each $\leq 4.7 \%$ of dose and all of them were also found in plasma.

\begin{tabular}{|c|c|c|c|c|c|c|c|c|c|c|c|c|c|}
\hline & \multicolumn{13}{|c|}{ \% Dose } \\
\hline & \multicolumn{4}{|c|}{$\begin{array}{c}\text { Mouse } \\
250 \mathrm{mg} / \mathrm{kg}\end{array}$} & \multicolumn{5}{|c|}{$\begin{array}{c}\text { Rat } \\
5 \mathrm{mg} / \mathrm{kg}\end{array}$} & \multicolumn{4}{|c|}{$\begin{array}{c}\text { Dog } \\
5 \mathrm{mg} / \mathrm{kg}\end{array}$} \\
\hline & \multicolumn{2}{|c|}{ Urine } & \multicolumn{2}{|c|}{ Feces } & \multicolumn{2}{|c|}{ Urine } & \multicolumn{2}{|c|}{ Feces } & \multirow{2}{*}{$\begin{array}{c}\text { Bile } \\
\mathrm{M}\end{array}$} & \multicolumn{2}{|c|}{ Urine } & \multicolumn{2}{|c|}{ Feces } \\
\hline & M & $\mathrm{F}$ & M & $\mathrm{F}$ & M & $\mathrm{F}$ & M & F & & M & $\mathrm{F}$ & M & $\mathrm{F}$ \\
\hline Empagliflozin & 2.2 & 16.2 & 9.5 & 10.5 & 6.9 & 10 & 18.0 & 21.3 & - & 9.6 & 7.1 & 19.5 & 16.3 \\
\hline M556/1 & 1.3 & 1.2 & - & - & 0.5 & 0.4 & - & - & 0.7 & 1.7 & 0.9 & - & - \\
\hline M498/1 & 0.9 & 0.7 & - & - & 0.1 & 1.2 & 0.5 & 5.9 & 0.3 & - & - & - & - \\
\hline M482/2 & - & - & - & - & - & - & - & - & - & 1.3 & 1.3 & 1.5 & 3.6 \\
\hline M482/1 & 17.5 & 15.6 & 23.6 & 19.0 & 9.8 & 5.9 & 21.4 & 16.3 & 28.4 & 11.3 & 6.8 & 21.0 & 25.5 \\
\hline M626/1 & - & - & - & - & - & - & - & - & - & 0.2 & $<0.1$ & - & - \\
\hline M478/1 & - & - & - & - & - & - & - & - & - & 0.1 & 0.1 & 0.6 & 0.8 \\
\hline M380/1 & 4.5 & 2.0 & 2.6 & 2.4 & 3.2 & 3.9 & 4.9 & 5.8 & 0.4 & 0.6 & 0.5 & 5.2 & 5.6 \\
\hline M468/1 & 2.9 & 1.3 & 2.7 & 1.0 & 1.8 & 2.2 & 3.1 & 3.7 & 0.2 & 1.0 & 0.6 & 1.8 & 1.5 \\
\hline M418/1 & - & - & - & - & 0.9 & 1.1 & 1.0 & 1.0 & - & - & - & - & - \\
\hline M626/2 & - & - & - & - & - & - & - & - & - & 0.5 & 0.1 & - & - \\
\hline M464/2 & - & - & - & - & - & - & - & - & - & 0.6 & 0.3 & 2.0 & 2.5 \\
\hline M464/3 & - & - & - & - & - & - & - & - & - & - & 0.1 & 0.4 & 1.6 \\
\hline M626/3 & - & - & - & 0.9 & - & - & - & - & - & 0.1 & 0.7 & - & - \\
\hline M464/1 & 4.7 & 3.8 & 8.1 & 5.4 & 3.6 & 3.5 & 11.7 & 5.0 & 1.3 & 1.1 & 0.2 & 7.1 & 11.0 \\
\hline Total $^{\star}$ & 34.0 & 40.8 & 46.5 & 39.2 & 26.8 & 28.2 & 60.6 & 59.0 & 31.3 & 28.2 & 18.7 & 59.1 & 68.4 \\
\hline
\end{tabular}

- Not detected * Remaining radioactivity was contributed by one or more metabolites, each $\leq 0.4 \%, \leq 0.9 \%$ and $\leq 0.2 \%$ dose in urine, feces and bile, respectively

Table 3: Relative distribution (\% dose) of empagliflozin and metabolites in urine, feces and bile from mice, rats and dogs after oral dosing of $\left[{ }^{14} \mathrm{C}\right]$ empagliflozin

\section{Metabolite profiles in feces}

Unchanged empagliflozin found in feces represented 9.5 - 10.5\% of the administrated dose in mice, 18.0 - $21.3 \%$ in rats, and 16.3 $19.5 \%$ in dogs (Table 3). Representative radiochromatogram of male rat feces is shown in Figure 2. As with plasma and urine, the number of metabolites in feces was higher in dogs than in mice or rats. M482/1 was the most abundant fecal metabolite in all the three species, and accounted for $19.0-23.6 \%, 16.3-21.4 \%$, and $21.0-25.5 \%$ dose in mice, rats and dogs, respectively. The second most abundant fecal metabolite in all the three species was M464/1, accounting for $5.0-11.7 \%$ dose. The remaining metabolites included M380/1, M468/1, M498/1, M482/2, M478/1, M418/1, M464/2, M464/3 and M626/3, and each was $\leq 5.8 \%$ of dose.

\section{Metabolite profiles in male rat bile}

The contributions to male rat bile radioactivity and percent of radioactive dose of unchanged empagliflozin and its metabolites are provided in Table 3. Biliary excretion accounted for 33.3\% of radioactive dose for male rats. In bile, no empagliflozin was found. The majority of the biliary radioactivity $(85.2 \%$ of bile radioactivity or $28.4 \%$ of radioactive dose) was contributed to by metabolite M482/1. The remaining bile radioactivity was accounted for by several metabolites. These bile metabolites were M464/1 (1.3\% of radioactive dose), M556/1 (0.7\% of radioactive dose), M498/1 (0.3\% of radioactive dose) and M380/1(0.4\% of radioactive dose) and M468/1(0.2\% of radioactive dose). The remaining metabolites each contributed less than $0.2 \%$ of the radioactive dose and were not further identified.

\section{Quantitative whole body autoradiography}

Following oral administration of $\left[{ }^{14} \mathrm{C}\right]$-empagliflozin to male pigmented rats at $5 \mathrm{mg} / \mathrm{kg}$, distribution of $\left[{ }^{14} \mathrm{C}\right]$-empagliflozinderived radioactivity to tissues was limited. The tissue concentrations of empagliflozin-derived total radioacitivity are provided in the supplementary material. Most radioactivities were found in the contents of the gastrointestinal tract and the major organs of excretion. The maximum mean blood and plasma concentrations were observed at 1 hour postdose. Mean concentrations of radioactivity in blood and plasma declined rapidly to low levels at 24 hours postdose and declined below the limit of quantitation 
by 72 hours postdose. All tissues with measurable concentrations of radioactivity had observed $\mathrm{C}_{\max }$ at the first sampling time at 1 hour postdose. The matrices with the highest concentrations of drug-derived radioactivity were gastrointestinal tract contents, urine, and bile. The highest average tissue $\mathrm{C}_{\max }$ values were measured in liver, renal cortex, kidney, renal medulla, and cecum with values of 4060, 2890, 2540, 2050, and 1470 ng equivalents/g, respectively. Radioactivity concentrations in central nervous system tissues protected by the blood-brain barrier (cerebellum, cerebrum, medulla, olfactory lobe, and spinal cord) were not measurable at any sampling time. $\left[{ }^{14} \mathrm{C}\right]$-empagliflozin-derived radioactivity was not associated with the melanin-containing tissues in the eye or skin. Elimination was complete for all tissues by 72 hours postdose. By the final sampling time of 168 hours postdose, no radioactivity was detected in any measured matrix. Terminal $t_{1 / 2}$ values for radioactivity could be estimated in 11 of the 52 matrices analyzed, with values ranging from 2.05 hours in liver to 8.86 hours in renal cortex.

\section{Metabolite identification}

Metabolite identification was based on HPLC retention time, radiochromatography and mass spectral analysis. High-resolution MS, MS/MS and $\mathrm{MS}^{3}$ analyses were performed for elemental composition determination and structure elucidation, and the results are summarized in Table 4. As the metabolite profiling was conducted over a span of 5 years in different Boeheringer Ingelheim laboratories and different lots of HPLC columns were used, retention time shifted from study to study. The retention times from the last profiling experiments are reported in the present paper.

\begin{tabular}{|l|l|l|l|l|}
\hline \multicolumn{1}{|c|}{ Metabolite } & \multicolumn{1}{|c|}{ Formula } & \multicolumn{1}{|c|}{ Diagnostic product ions $\left(\mathbf{M S}^{2} \text { and } \mathbf{M S}^{3}\right)^{*}$} & \multicolumn{1}{c|}{ Biotransformation Pathways } & \multicolumn{1}{c|}{ Species } \\
\hline Empagliflozin & $\mathrm{C}_{23} \mathrm{H}_{26} \mathrm{O}_{7} \mathrm{Cl}$ & $413,395,383,379,371,359,329$ & - & mouse, rat, dog \\
\hline $\mathrm{M} 556 / 1$ & $\mathrm{C}_{25} \mathrm{H}_{28} \mathrm{O}_{12} \mathrm{Cl}$ & $379,361,319,301,289,259,247$ & Glucuronidation & mouse, dog \\
\hline $\mathrm{M} 498 / 1$ & $\mathrm{C}_{23} \mathrm{H}_{28} \mathrm{O}_{10} \mathrm{Cl}$ & $395,359,341,329,317,305,275,263$ & Carboxylation & mouse, rat \\
\hline $\mathrm{M} 482 / 2$ & $\mathrm{C}_{23} \mathrm{H}_{26} \mathrm{O}_{9} \mathrm{Cl}$ & $379,361,319,301,289,259$ & Oxidation & mouse, dog \\
\hline $\mathrm{M} 482 / 1$ & $\mathrm{C}_{23} \mathrm{H}_{26} \mathrm{O}_{9} \mathrm{Cl}$ & $379,361,319,301,289,259$ & Oxidation & mouse, rat, dog \\
\hline $\mathrm{M} 626 / 1$ & $\mathrm{C}_{29} \mathrm{H}_{34} \mathrm{O}_{13} \mathrm{Cl}$ & $565,507,449,395,371,343,329,301$ & Glucuronidation & dog \\
\hline $\mathrm{M} 478 / 1$ & $\mathrm{C}_{23} \mathrm{H}_{22} \mathrm{O}_{9} \mathrm{Cl}$ & $393,313,289,259,345,231$ & Oxidation-dehydrogenation & dog \\
\hline $\mathrm{M} 380 / 1$ & $\mathrm{C}_{19} \mathrm{H}_{20} \mathrm{O}_{6} \mathrm{Cl}$ & $343,325,319,313,301,289,259,247$ & dealkylation & mouse, rat, dog \\
\hline $\mathrm{M} 468 / 1$ & $\mathrm{C}_{23} \mathrm{H}_{28} \mathrm{O}_{8} \mathrm{Cl}$ & $379,343,325,319,313,301,289,259,247$ & Oxidation & mouse, rat, dog \\
\hline $\mathrm{M} 418 / 1$ & $\mathrm{C}_{23} \mathrm{H}_{29} \mathrm{O}_{7}$ & $381,363,345,333,321$ & deschlorination & rat \\
\hline $\mathrm{M} 626 / 2$ & $\mathrm{C}_{29} \mathrm{H}_{34} \mathrm{O}_{13} \mathrm{Cl}$ & $565,507,449,395,371,343,329,301$ & Glucuronidation & dog \\
\hline $\mathrm{M} 464 / 2$ & $\mathrm{C}_{23} \mathrm{H}_{24} \mathrm{O}_{8} \mathrm{Cl}$ & $387,383,359,341,329,327,313,301$ & Oxidation-dehydrogenation & mouse, dog \\
\hline $\mathrm{M} 464 / 3$ & $\mathrm{C}_{23} \mathrm{H}_{24} \mathrm{O}_{8} \mathrm{Cl}$ & $419,387,379,361,341,325,313,301,287,259$ & Oxidation-dehydrogenation & dog \\
\hline $\mathrm{M} 626 / 3$ & $\mathrm{C}_{29} \mathrm{H}_{34} \mathrm{O}_{13} \mathrm{Cl}$ & $565,507,449,395,371,343,329,301$ & Glucuronidation & mouse, rat, dog \\
\hline $\mathrm{M} 464 / 1$ & $\mathrm{C}_{23} \mathrm{H}_{26} \mathrm{O}_{8} \mathrm{Cl}$ & $429,411,393,381,369,345,331,191$ & Oxidation-dehydrogenation & mouse, rat, dog \\
\hline
\end{tabular}

* Mass spectral data were obtained in positive mode for M464/1 and M418/1 and negative mode for all other metabolites and empagliflozin

Table 4: Mass spectral analysis of empagliflozin metabolites in mice, rats and dogs

Empagliflozin: The radioactive peak eluting at approximately 59.0 minutes in all matrices corresponded to empagliflozin, as it had a similar retention time, identical MS and MS/MS patterns as authentic standard. The molecular ion was found at $\mathrm{m} / \mathrm{z} 451 \mathrm{in}$ positive mode and m/z 449 in negative mode, both with an isotope ratio of roughly 0.35 for [M+2]/M which was characteristic for a molecular ion containing one chlorine atom. As shown in Figure 3, the positive MS/MS of empagliflozin produced several abundant fragment ions, which included fragments at m/z $415\left(-2 \mathrm{H}_{2} \mathrm{O}\right), 397\left(-3 \mathrm{H}_{2} \mathrm{O}\right), 385\left(2 \mathrm{H}_{2} \mathrm{O}-\mathrm{CH}_{2} \mathrm{O}\right), 379\left(-4 \mathrm{H}_{2} \mathrm{O}\right), 367$ $\left(-3 \mathrm{H}_{2} \mathrm{O}-\mathrm{CH}_{2} \mathrm{O}\right)$ and the glucose ring-opened fragments at $\mathrm{m} / \mathrm{z} 373,355,331$ and 287 . The majority of these fragmentations were also observed in the negative MS/MS as indicated by the presence of negative fragments at $\mathrm{m} / \mathrm{z} 413,395,383,371,359$ and 329 (Table 4). In addition, the negative MS/MS showed the loss of the furan ring, corresponding to the $\mathrm{m} / \mathrm{z} 379$ ion. These characteristic fragmentations were useful in structure elucidation for metabolites as discussed below.

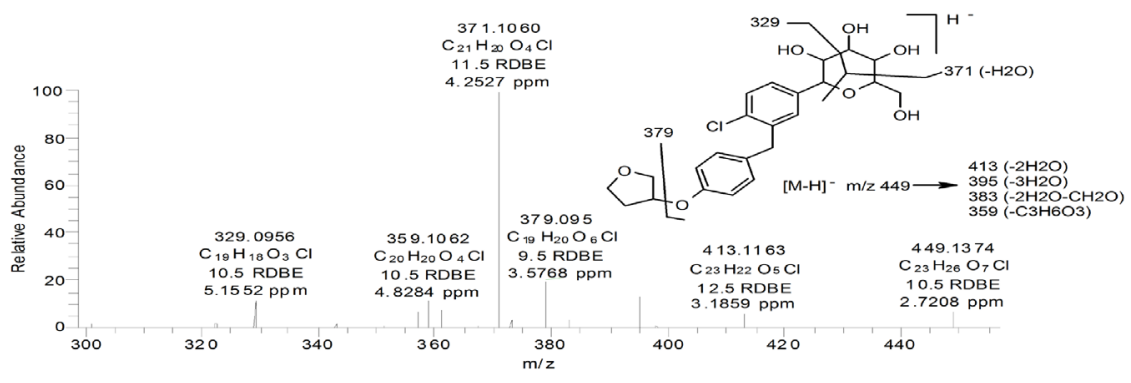

Figure 3: Negative MS/MS of empagliflozin reference standard 
M498/1: It corresponded to a negative molecular ion at $\mathrm{m} / \mathrm{z} 497,48$ daltons (+3O) more than empagliflozin. The negative MS/ MS gave fragments at $\mathrm{m} / \mathrm{z} 395,377,359,299$, and 257 (table 4), suggesting addition of 32 daltons (2O) to the furan ring and 16 dalton (O) to one of the aromatic rings. Based on the mass spectral analyses, M498/1 was tentatively identified to be an oxidized metabolite of M482/1 or M482/1.

M556/1: The negative molecular ion of M556/1 at m/z 555 corresponded to and an elemental composition of $\mathrm{C}_{25} \mathrm{H}_{28} \mathrm{O}_{12} \mathrm{Cl}_{\text {. Negative }}$ MS/MS of M556/1 gave a product ion at m/z 379 via loss of $176 \mathrm{Da}$ (glucuronide), and m/z 301 and 259 (Table 4). The MS ${ }^{3}$ (not shown) for the $\mathrm{m} / \mathrm{z} 379$ product ion was identical to the MS/MS of M380/1. Based on the MS analyses, M556/1 was identified to be a glucuronide conjugate of M380/1.

M482/1 and M482/2: Both metabolites had negative molecular ions at $\mathrm{m} / \mathrm{z} 481$ and contained two additional oxygen atoms (32 $\mathrm{Da}$ ) compared to empagliflozin. The negative MS/MS of M482/1 and M482/2 were quite similar, showing fragments at $\mathrm{m} / \mathrm{z} 379$, 361, 319, 301, and 259 (Table 4), and suggested that M482/1 and M482/2 were two isomers. The $\mathrm{m} / \mathrm{z} 379$ fragment corresponded to the furan-less moiety of the molecule in both $\mathrm{M} / 482 / 1$ and $\mathrm{M} 482 / 2$, which indicated that the double oxidation occurred on the tetrahydrofuran ring. The oxidation led to subsequent ring opening and yielded two carboxylic acid metabolites M482/1 and M482/2.

M626/1, M626/2 and M626/3: These three metabolites were isomers with negative molecular ions at $\mathrm{m} / \mathrm{z} 625$ and an elemental composition of $\mathrm{C}_{29} \mathrm{H}_{34} \mathrm{O}_{13} \mathrm{Cl}$. As they were $176 \mathrm{Da}$ higher than empagliflozin, they were apparently empagliflozin glucuronide conjugates. They gave similar MS/MS fragmentation patterns (Table 4). The presence of daughter ions at $\mathrm{m} / \mathrm{z} 371$ and 329 suggested that the glucuronidation was on the glucose moiety. The structures of these 3 glucuronidation metabolites have been confirmed with respective authentic standards.

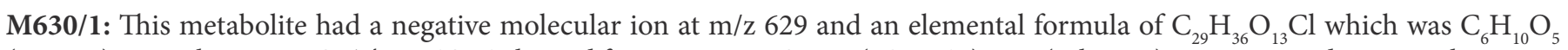
$(162 \mathrm{Da})$ more than M468/1. The MS/MS showed fragments at $\mathrm{m} / \mathrm{z} 551\left(-\mathrm{C}_{2} \mathrm{H}_{4} \mathrm{O}_{3}\right), 467$ (-glucose), 379, 361, and 301. Furthermore, the $\mathrm{MS}^{3}$ of the fragment at $\mathrm{m} / \mathrm{z} 467$ showed a predominant fragment at $\mathrm{m} / \mathrm{z} 379$ (Table 4 ), same as the MS/MS of M468/1. The mass spectral data suggested that M630/1 was a glucose conjugated M468/1.

M478/1: This metabolite corresponded to a negative molecular ion $\mathrm{m} / \mathrm{z} 477$ and an elemental composition of $\mathrm{C}_{23} \mathrm{H}_{22} \mathrm{O}_{9} \mathrm{Cl}$. The $\mathrm{MS} /$ MS gave a predominate product ion at $\mathrm{m} / \mathrm{z} 393$, which in $\mathrm{MS}^{3}$ further produced M380/1-characteristic fragments such as 313, 289, 259 and 231 (Table 4). The mass spectral data was consistent with a lactone-carboxylic acid metabolite.

M380/1: M380/1 co-eluted with M468/1. M380/1 corresponded to a negative molecular ion at $\mathrm{m} / \mathrm{z} 379$ and an elemental composition of $\mathrm{C}_{19} \mathrm{H}_{20} \mathrm{O}_{6} \mathrm{Cl}$. The MS/MS gave characteristic glucose ring-opened fragments at $\mathrm{m} / \mathrm{z} 319$, 301, 259, etc. (Table 4). It had same retention time, elemental composition and MS/MS to the authentic standard, and was thus identified as a destetrahydrofuranyl metabolite.

M468/1: As discussed above, this metabolite co-eluted with M380/1. The negative molecular ion of M468/1 at m/z 467 was 18 Da $\left(\mathrm{H}_{2} \mathrm{O}\right)$ greater than empagliflozin. The negative MS/MS showed a predominant fragment at $\mathrm{m} / \mathrm{z} 379$ (Table 4 ). The $\mathrm{MS} 3$ for the $\mathrm{m} / \mathrm{z}$ 379 product ion was identical to the MS/MS of M380/1. The mass spectral data of M468/1 were consistent with a tetrahydrofuran ring-opened dihydroxyl structure.

M418/1: The positive molecular ion of M418/1 at m/z 417 was 34 daltons less than BI 10773, indicating a dechlorination metabolite. The positive MS/MS of M418/1 gave fragments at m/z 381, 363, 345, 333, and 321; each was 34 Dalton's less than its corresponding fragment from empagliflozin (Table 4). The mass spectral data were consistent with the dechlorination structure.

M464/1, M464/2 and M464/3: The positive molecular ion at m/z 465 from M464/1and negative molecular ions at m/z 463 from M464/2 and M464/3 were 14 Da higher than empagliflozin. The three metabolites had same elemental composition of $\mathrm{C}_{23} \mathrm{H}_{26} \mathrm{O}_{8} \mathrm{Cl}_{\text {, }}$ with one additional oxygen and two fewer hydrogens $(+\mathrm{O}-2 \mathrm{H})$ than empagliflozin. The MS/MS of M464/1 showed fragments at $\mathrm{m} / \mathrm{z} 429,411,393,381,369$ and 345, indicating that the $[+\mathrm{O}-2 \mathrm{H}]$ unit was not on the glucose ring (Table 4). M464/1 was thus a product of hydroxylation followed by dehydrogenation. Negative MS/MS of M464/2 gave empagliflozin characteristic fragments. The presence of $\mathrm{m} / \mathrm{z} 383$ fragments suggested the presence of a carboxylic group on the glucose moiety. M464/2 was thus identified to be a carboxylic acid metabolite on the 6-position of the glucose moiety. In contrast to M464/1 and M464/2, MS/MS of M464/3 gave M380/1-type fragments such as $\mathrm{m} / \mathrm{z} 379$ and 301. The MS/MS data suggested that the [+O-2H] modification in M464/3 was on the tetrahydrofuran ring, which was consistent with a lactone metabolite.

\section{Discussion}

Empagliflozin was well absorbed after oral administration in male and female CD-1 mice, male Wistar rats, and male beagle dogs. The clearance of empagliflozin was low in dog and moderate in rat and mouse. Volume of distribution and half-life were generally moderate in all species. Oral bioavailability was moderate in rat (31\%) and high in mouse (90-97\%) and dog (89\%). The difference in oral bioavailability between rats and mice was likely due to two factors. First, the doses were very different, $250 \mathrm{mg} / \mathrm{kg}$ in the mouse compared to $5 \mathrm{mg} / \mathrm{kg}$ in the rat. The absorption of drug could be saturated at such a high dose. In addition, any transporter efflux or first pass metabolism is likely saturated at $250 \mathrm{mg} / \mathrm{kg}$. 
In CD-1 mice and Wistar Han rats, the half-life of empagliflozin-derived radioactivity after IV administration was $<1 \mathrm{~h}$ for both sexes. This was similar to the half-life of empagliflozin, suggesting that most of the circulating radioactivity was parent compound. The terminal $t_{1 / 2}$ of empagliflozin-derived radioactivity after oral dosing at in mice and rats was longer than that of empagliflozin, suggesting that some of the metabolites were longer-lived than parent. The terminal half-life in Wistar Han rats after oral dosing at $5 \mathrm{mg} / \mathrm{kg}$ was short, at $1.98 \mathrm{~h}$ for males and $3.73 \mathrm{~h}$ for females.

Distribution of $\left[{ }^{14} \mathrm{C}\right]$-empagliflozin -derived radioactivity to tissues was limited. Most radioactivities were found in the contents of the gastrointestinal tract and the major organs of excretion. The maximum mean blood and plasma concentrations were observed at 1 hour postdose.

Following dosing of $\left[{ }^{14} \mathrm{C}\right]$-empagliflozin to dogs, the plasma terminal phase $\mathrm{t}_{1 / 2}$ values for radioactivity were $22.0 \mathrm{~h}$ in males and $31.2 \mathrm{~h}$ in females following IV administration and $3.60 \mathrm{~h}$ in males and $5.16 \mathrm{~h}$ in females following oral administration. The data show no gender differences in the systemic exposure to drug-derived radioactivity. The shorter half-life observed in orally dosed animals than in intravenously dosed dogs is due to the lower limit of quantitation found in the intravenously dosed animals, which enabled a larger portion of the terminal elimination phase to be measured. Following oral administration, absorption of $\left[{ }^{14} \mathrm{C}\right]-$ empagliflozin derived radioactivity was 102 and $92.1 \%$ in males and females, respectively.

The elimination of drug-derived radioactivity in dogs following intravenous and oral administration of $\left[{ }^{14} \mathrm{C}\right]$-empagliflozin was similar and occurred primarily in feces, representing a mean of 61.4 to $70.9 \%$ of dose. Most of the administered dose was eliminated in the first $24 \mathrm{~h}$ post-dose, with means of $71.9 \%$ (males) and $82.0 \%$ (females) for the IV doses and $83.6 \%$ (males) and $75.4 \%$ of dose (females) for the oral dose. Similarly, fecal elimination was the major route in rats (69.4 - 79.7\% dose) and mice (79.4 - $81.7 \%)$, and there were no apparent gender differences.

Metabolite profiles in plasma, urine, bile and feces were similar across mice, rats and dogs, although more metabolites were formed in dogs. The most abundant metabolite in all three species was the oxidation metabolites M482/1. Several minor metabolites were found in dog but not in mouse and rat. For each species, no apparent gender differences in metabolic pattern were observed.

In human healthy subjects, unchanged empagliflozin was the most abundant drug-related component in plasma (79.6\% total plasma radioactivity), urine $(23.7 \%$ dose $)$ and feces (34.2\% dose) following a single oral dose of $\left[{ }^{14} \mathrm{C}\right]$-empagliflozin [14]. No major circulating metabolites, but only several minor metabolites, were detected in the human plasma. These minor metabolites included three glucuronide conjugates (M626/1, M626/2, M626/3), M482/1, M464/1 and M468/1. No single metabolite was therefore considered major in humans that could require non-clinical safety assessments, as defined by its presence in plasma at more than $10 \%$ of total drug-related material at steady state, which is specified by the FDA Guidance on "Safety Testing of Drug Metabolites" [15] and the ICH Guidance on "Nonclinical safety studies for the conduct of human clinical trials and marketing authorization for pharmaceuticals, M3 (R2)" [16]. Compared to humans, metabolic pathways involving oxidation were much more prominent in mice, rats and dogs. In addition within the $\mathrm{C}^{14}$-labeled ADME studies conducted for empagliflozin, M380/1, M464/2, M464/3, M478/1, M482/2, and M556/1 were found only in animal species.

Biotransformation of empagliflozin in mice, rats and dogs mainly involved oxidation as well as glucuronide and glucose conjugation (Figure 4). Oxidation on the tetrahydrofuran ring followed by ring-opening, possibly via an aldehyde intermediate (not detected), led to the formation of dihydroxyl metabolite M468/1 and its glucose conjugate M630/1, carboxylic acid metabolites M482/1 and M482/2, and subsequent metabolites M463/3 and M478/1. Oxidation on the tetrahydrofuran ring followed by O-dealkylation resulted in the formation of M380/1, which further gave glucuronide conjugate M556/1. Oxidation on the glucose moiety resulted in the formation of carboxylic acid metabolite M464/2. Oxidation was also responsible for the formation of M464/1. In addition, empagliflozin underwent direct glucuronide conjugation, to a much lesser extent, to form M626/1, M626/2 and M626/3.

\section{Conclusion}

Empagliflozin was well absorbed after oral administration in CD-1 mice, Wistar rats, and beagle dogs. The clearance of empagliflozin, determined following IV administration, was low in dogs. The volume of distribution and half-life of total radioactivity were generally moderate in all species. The oral bioavailability of total radioactivity was moderate in rats and high in mice and dogs. Excretion patterns were generally similar in males and females across species evaluated. Feces was the primary route of excretion of $\left[{ }^{14} \mathrm{C}\right]$-empagliflozin-derived radioactivity. Distribution of $\left[{ }^{14} \mathrm{C}\right]$-empagliflozin-derived radioactivity to tissues was limited. Most radioactivities were found in the contents of the gastrointestinal tract and the major organs of excretion. The maximum mean blood and plasma concentrations were observed at 1 hour postdose. There was no binding to melanain.

Metabolite profiles in plasma, urine, bile and feces were similar across mice, rats and dogs. Biotransformation of empagliflozin mainly involved oxidation as well as glucuronide and glucose conjugation. Several minor metabolites were found in dog but not in mouse and rat. All the human metabolites found in a human ADME study were present in the animal species. 

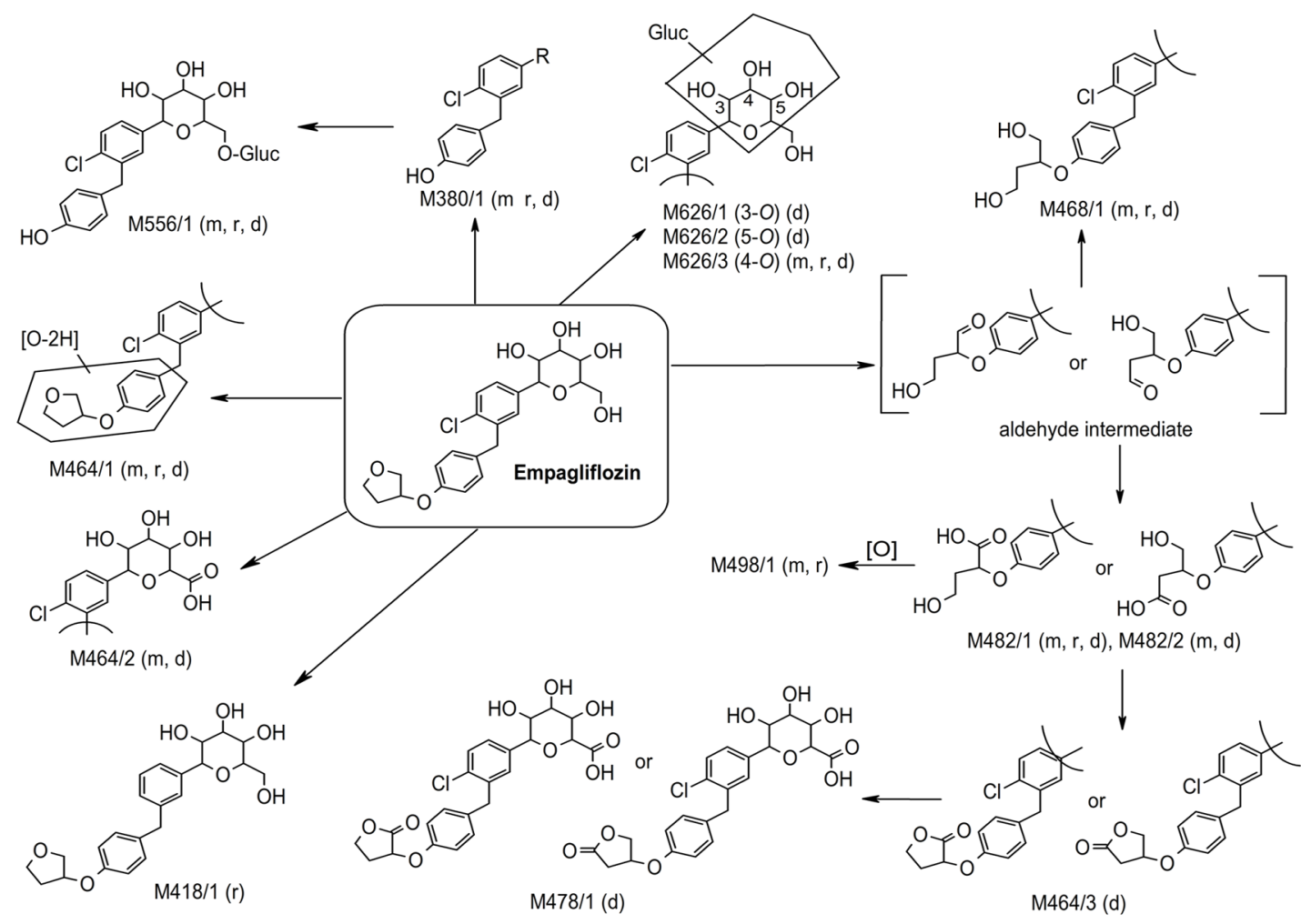

m: mouse; r: rat; d: dog

Figure 4: Metabolic pathways of empagliflozin in mice, rats and dogs

\section{Acknowledgement}

The authors would like to thank Dr. Bachir Latli for synthesis and purification of $\left[{ }^{14} \mathrm{C}\right]$ empagliflozin and Susanne Kallbach for her contributions to metabolite profiling/id. We also thank Drs. Donald Tweedie and Mitchell Taub for their valuable input. The mouse and rat PK studies were conducted at Boehringer Ingelheim Pharmaceutical, Inc. The mouse mass balance study was conducted by XenoBiotic Laboratories, Inc. The rat QWBA and rat and dog mass balance and PK studies were conducted by Covance Laboratories Inc. Metabolite profiling and identification was carried out at Boehringer Ingelheim Pharmaceuticals, Inc., and Boehringer Ingelheim Pharma GmbH \& Co. KG. Financial support of this study was provided by Boehringer Ingelheim Pharmaceuticals, Inc.

\section{Click here to download Supplementary File}

\section{References}

1. DeFronzo RA (2009) From the Triumvirate to the Ominous Octet: A New Paradigm for the Treatment of Type 2 Diabetes Mellitus. Diabetes 58: 773-95.

2. International Diabetes Federation Diabetes Atlas Six edition (2013) Executive Summary, Belgium.

3. Inzucchi SE, Bergenstal RM, Buse JB, Diamant M, Ferrannini E, et al. (2012) Management of hyperglycemia in type 2 diabetes: a patient-centered approach: position statement of the American Diabetes Association (ADA) and the European Association for the Study of Diabetes (EASD). Diabetes Care 35: 1364-79.

4. Esposito K, Chiodini P, Bellastella G, Maiorino MI, Giugliano D (2012) Proportion of patients at HbA1c target $<7 \%$ with eight classes of antidiabetic drugs in type 2 diabetes: systematic review of 218 randomized controlled trials with 78945 patients. Diabetes Obes Metab 14: 228-33.

5. DeFronzo RA, Davidson JA, Del Prato S (2012) The role of the kidneys in glucose homeostasis: a new path towards normalizing glycaemia. Diabetes Obes Metab 14: 5 -14.

6. Gerich JE (2010) Role of the kidney in normal glucose homeostasis and in the hyperglycaemia of diabetes mellitus: therapeutic implications. Diabet Med 27: 136-42.

7. Grempler R, Thomas L, Eckhardt M, Himmelsbach F, Sauer A, et al. (2012) Empagliflozin, a novel selective sodium glucose cotransporter-2 (SGLT-2) inhibitor: characterisation and comparison with other SGLT-2 inhibitors. Diabetes Obes Metab 14: 83-90.

8. Heise T, Seewaldt-Becker E, Macha S, Hantel S, Pinnetti S, et al. (2013) Safety, tolerability, pharmacokinetics and pharmacodynamics following 4 weeks' treatment with empagliflozin once daily in patients with type 2 diabetes. Diabetes Obes Metab 15: 613-21.

9. Roden M, Weng J, Eilbracht J, Delafont B, Kim G, et al. (2013) Empagliflozin monotherapy with sitagliptin as an active comparator in patients with type 2 diabetes: a randomised, double-blind, placebo-controlled, phase 3 trial. Lancet Diabetes Endocrinol 1: 208-19.

10. Barnett AH, Mithal A, Manassie J, Jones R, Rattunde H, et al. (2014) Efficacy and safety of empagliflozin added to existing antidiabetes treatment in patients with type 2 diabetes and chronic kidney disease: a randomised, double-blind, placebo-controlled trial. Lancet Diabetes Endocrinol 2: 369-84.

11. Häring HU, Merker L, Seewaldt-Becker E, Weimer M, Meinicke T, et al. (2013) Empagliflozin as add-on to metformin plus sulfonylurea in patients with type 2 diabetes: a 24-week, randomized, double-blind, placebo-controlled trial. Diabetes Care 36: 3396-404.

12. Häring HU, Merker L, Seewaldt-Becker E, Weimer M, Meinicke T, et al. (2014) Empagliflozin as add-on to metformin in patients with type 2 diabetes: a 24week, randomized, double-blind, placebo-controlled trial. Diabetes Care 37: 1650-9. 
13. Kovacs CS, Seshiah V, Swallow R, Jones R, Rattunde H, et al. (2014) Empagliflozin improves glycaemic and weight control as add-on therapy to pioglitazone or pioglitazone plus metformin in patients with type 2 diabetes: a 24-week, randomized, placebo-controlled trial. Diabetes Obes Metab 16: 147-58.

14. Chen LZ, Jungnik A, Mao Y, Philip E, Sharp D, et al (2015) Biotransformation and mass balance of the SGLT2 inhibitor empagliflozin in healthy volunteers. Xenobiotica 30: 1-10.

15. FDA (2008) Guidance for Industry: Safety Testing of Drug Metabolites.

16. ICH (2008) Topic M3 (R2): Non-clinical safety studies for the conduct of human clinical trials and marketing authorization for pharmaceuticals.

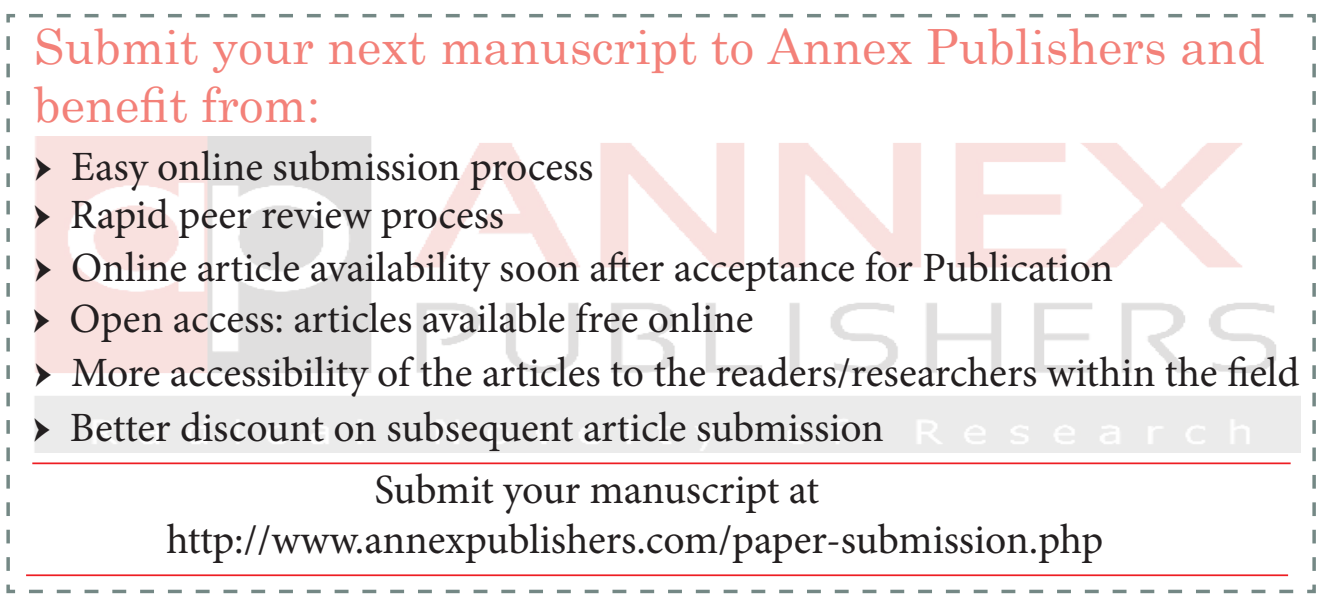

